\title{
Mondor's Disease of the Chest Wall- A Forgotten Cause of Chest Pain: Clinical Approach and Treatment
}

\section{Bennidor Raviv* and Shlomo Hanan Israelit}

Department of Emergency Medicine, Rambam Medical Center, Haifa, Israel

*Corresponding author: Bennidor Raviv, Emergency Department, Rambam Health Care Campus, POB 9602, Haifa 31096, Israel, Tel: +97248542309; Fax: +97248543123; E-mail: b_raviv@rambam.health.gov.il

Received date: Mar 22, 2014, Accepted date: Apr 22, 2014, Published date: Apr 26, 2014

Copyright: (c) 2014 Raviv B, et al. This is an open-access article distributed under the terms of the Creative Commons Attribution License, which permits unrestricted use, distribution, and reproduction in any medium, provided the original author and source are credited.

\begin{abstract}
Mondor's disease is superficial thrombophlebitis involving the chest wall, breast, abdomen and penis. It is an entity and unknown to many physicians and considered under diagnosed and under reported. In recent years the therapeutic approach to superficial venous thrombosis is changing. In this article we discuss the presentation of this condition in the chest wall, etiology, epidemiology, diagnosis and treatment. We believe that by familiarity of physicians with Mondor's disease will help them in the diagnosis and treatment of patients, and also with reporting and building a data base for further research.
\end{abstract}

Keywords: Mondor's disease; Thrombophlebitis; Chest pain; Anticoagulation

\section{Introduction}

Mondor's disease is thrombophlebitis of superficial veins or lymphatic vessels, mostly of the chest wall or breast, although it can involve other areas, such as the neck, abdomen and penis. In this review we concentrate on the diagnostic and therapeutic approach of only the chest wall, though much is common with presentation in other regions of the body. The condition was first described by Henry Mondor (Figure 1), a French surgeon in 1939[it was first described by Faage in 1869 as a form of scleroderma] [1,2].

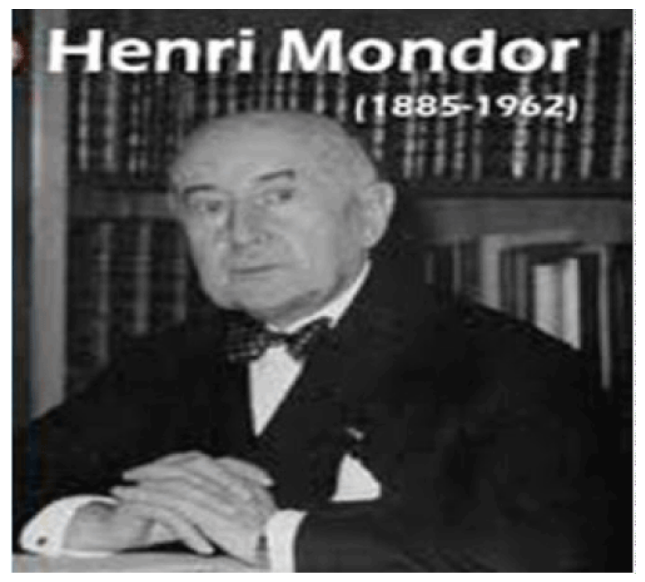

Figure 1: Henry Mondor.

It is a rare condition, with one review describing fewer than 400 cases since the first description by Mondor in 1939 until 2009 [3]. Although it is considered to be rare, there are suspicions that its prevalence in the population is actually higher, and it is under reported due to its relatively benign course and good prognosis [4].
Many [probably most] physicians are not familiar with the condition, and thus don't seek for it, and don't consider it in the differential diagnosis of patients presenting with relevant clinic. Pathogenesis, etiology, and epidemiology: the pathophysiological process involves inflammation and thrombosis of superficial venous and lymphatic vessels, mostly of the anterolateral chest wall or breast, but also in other locations, as mentioned above $[3,4]$.

Resolution of symptoms follows re canalization of the vessel.

Some authors divide the pathophysiological process into four discrete stages:

i) Thrombus formation, thrombus organization, partial re canalization, and re canalized vein with fibrous wall [3-5].

ii) The most common venous vessels involved in the chest wall are the lateral thoracic, thoracoepigastric, and superior epigastric veins [5].

iii) While many conditions are mentioned as possible etiologies (Table 1), at least half of the cases are idiopathic [5-10].

iv) The disease is more prevalent in women than in men [up to a ratio of 3:1 described by some series], and mostly presents in middle aged patients [11-13].

\begin{tabular}{|l|l|}
\hline S.No & Etiologies of mondor's disease \\
\hline 1 & Idiopathic \\
\hline 2 & Trauma \\
\hline 3 & Infections: bacterial, viral [herpes zoster] \\
\hline 4 & Intravenous drug injection \\
\hline 5 & Vasoconstriction drugs \\
\hline 6 & $\begin{array}{l}\text { Rheumatologic diseases: systemic lupus erythematosus, } \\
\text { scleroderma, rheumatoid arthritis. }\end{array}$ \\
\hline 7 & $\begin{array}{l}\text { Surgery of breast and chest wall, [including mamoplasty and } \\
\text { excision breast biopsies, especially using the tunnel procedure]. }\end{array}$ \\
\hline
\end{tabular}




\begin{tabular}{|l|l|}
\hline 8 & Tight clothes \\
\hline 9 & Hyper coagulation states \\
\hline 10 & Malignancy \\
\hline 11 & Electrocution \\
\hline
\end{tabular}

Table 1: Etiologies of mondor's disease of the chest wall.

Clinical presentation, course, and outcomes: the presentation is of a hard, palpable cord along the anterolateral chest wall. The cord may be only a few centimeters of length, or it may be as long as thirty centimeters $[3,5,6,12]$ (Figure 2).

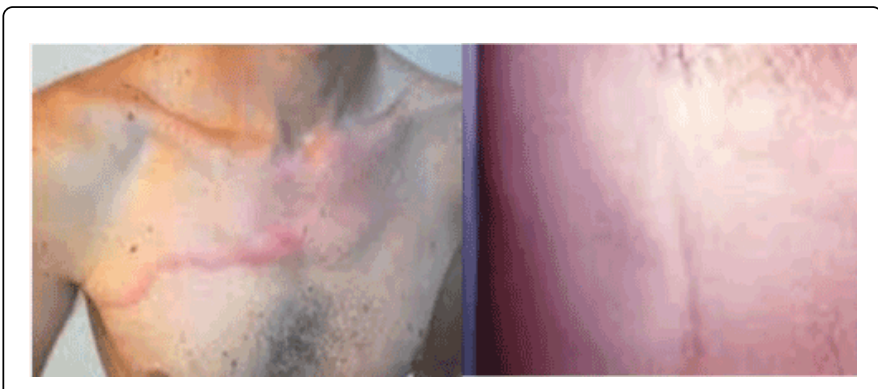

Figure 2: Superficial thrombophlebitis of the chest wall

i) Many times the presentation is painless, but pain is not rare, and it commonly precedes the appearing of the cord.

ii) The pain is aggravated by motion and touching the cord.

iii) Sometimes there is dyspnea as part of the complaints.

iv) There is commonly tenderness along the course of the cord, but it can be a totally painless condition.

v) Usually there is no, or minimal, erythema of the skin around the lesion, though there are reports of considerable inflammation and infections [13].

vi) Low grade fever and axillary adenopathy have been described in some cases [14].

vii) The clinic usually resolves during the course of a few weeks [2-10], even with no medical intervention.

viii) The occurrence of pulmonary embolism after Mondor's disease is non-significant according most authors, and the recurrence rate of thrombophlebitis is less than $3 \%$, but the condition can be part of systemic superficial thrombophlebitis syndrome $[4,15]$.

\section{Diagnostic considerations}

The diagnosis may be made on clinical grounds. The differential diagnosis includes mainly inflammatory processes of arteries - angeitis - whether infectious/septic, rheumatologic [polyarteritis nodosa] or secondary to drugs $[4,13]$. Ultrasonography may be of great assistance, demonstrating superficial venous thrombosis, differentiating veins from lymphatic ducts, making treatment decisions, and ruling out masses compressing the vessels [16].

When another pathologic process is considered, or ultrasonography is not diagnostic, biopsies can be taken and there are immunohistochemical staining available to differentiate venous and lymphatic vessels [CD 31, CD 34 antibodies, and von villebrand factor antibodies] [3,4,13].

There is no consensus in the literature regarding additional mandatory studies, although most authors recommend completing evaluation for hypercoagulable states and for breast malignancy [there are many descriptions of breast cancer associated with Mondor's disease, and case series reporting prevalence of between 0 and 13\%], especially in cases with no obvious etiology [trauma, surgery] $[4,9,13,15]$.

\section{Treatment}

Traditionally, most authors recommended no specific treatment for superficial thrombophlebitis of the chest wall, but lately, with large studies showing improved outcomes by treating superficial thrombophlebitis of the lower limbs with systemic anticoagulant medicine, when compared to no treatment [17], and latest recommendations and guidelines indicate systemic anticoagulation $[18,19]$, there may be a change in the treatment of thrombophlebitis of the chest wall, though due to the rarity of the condition it is hard to believe large trials will be conducted on the issue.

Anatomically, there is less chance of progressing to deep vein thrombosis in the chest than in the lower limbs, although the rates of this complication in the systemic anticoagulation trials for superficial thrombophlebitis of the lower limbs were also very low in the placebo groups [17-19].

These studies also showed significantly less local complications with treatment, such as lower rates of need for surgical interventions, lower local progression of the thrombosis, and lower recurrence rates.

These benefits are achieved without significant increase in adverse effects [major bleeding due to anticoagulation] - the anticoagulation is recommended for a limited period of time - 30 to 45 days, and in lower dosage than for deep vein thrombosis $[17,18]$.

Also, it should be noted, that at least in part of these studies, high risk populations for complications of thrombosis [oncologic patients, patients with thrombosis proximal to the sapheno femoral junction and others] were excluded [20].

It is worth to notice that in the legs, Systemic anticoagulation treatment is recommended only for thrombosis longer than $5 \mathrm{~cm}$ in patients with no risk factors for complications.

Longer duration of treatment and higher dosage of anticoagulants are recommended for patients in risk for systemic thrombosis [i.e. oncologic patients, hyper coagulation states, immobile] $[18,19]$.

Due to these benefits, it is reasonable to treat thrombophlebitis of the chest wall with systemic anticoagulants, but since no specific guidelines exist specifically for this condition, a consultation with hematologists in the local institution can be made for each case.

Although the best information about anticoagulation for superficial vein thrombosis regards fundaparinux [ $2.5 \mathrm{mg}$ daily for 30 to 45 days - a low "prophylactic" dosage], other studies, though of lower quality, showed similar outcomes [less complications of thrombosis with comparable rates of treatment adverse effects] with LMWH and unfractioned heparin [21-23].

There is yet not sufficient data about the new oral direct thrombin inhibitors and activated factor $\mathrm{X}$ inhibitors for the treatment of thrombophlebitis. 
Citation: Raviv B, Israelit SH (2014) Mondor's Disease of the Chest Wall- A Forgotten Cause of Chest Pain: Clinical Approach and Treatment. J Gen Pract 2: 157. doi:10.4172/2329-9126.1000157

Page 3 of 3

Additional treatment measures for longer than $5 \mathrm{~cm}$ thromboses, and for shorter thrombosis are local NSAIDS preparations, systemic analgesics, or local anesthetic infiltration around the lesion.

Local anticoagulation preparations may be used when no systemic treatment is given, in order to accelerate recanalization rates. The use of antibiotics is not advocated unless there is clear evidence of infection [13-15].

Surgical measures have been advocated in cases of intractable pain, infection unresponsive to antibiotics, or local vascular complications [and as mentioned above, the need for surgery has been shown to significantly decrease with the routine use of systemic anticoagulation].

\section{Conclusions}

Mondor's disease is an underreported and unknown etiology of chest pain. The diagnosis is straight forward once the physician is considering it in the differential diagnosis. Recent changes in the approach to superficial thrombophlebitis favor systemic, low dose anticoagulation for the condition, in contrast to past recommendations that favored only analgesics. Although usually selflimited, it is important to bear in mind that a significant number of cases may be related to malignancy, mostly of the breast, and there is need to exclude this option, as the possibility of systemic hyper coagulation states.

Recognizing the condition can save the patient and the health care system unnecessary investigations, pain and treatments, and provide adequate investigation and follow up for patients who need it.

\section{References}

1. Mondor H (1939) Tronculite sous cutane'e subaigue de la paroi thoracique ante ro-late. Mem Acad Chir 65: 1271-1278.

2. Herrmann JB (1966) Thrombophlebitis of breast and contiguous thoracicoabdominal wall (Mondor's disease). N Y State J Med 66: 3146-3152.

3. Quéhé P, Saliou AH, Guias B, Bressollette L (2009) [Mondor's disease, report on three cases and literature review]. J Mal Vasc 34: 54-60.

4. A'lvarez-Garrido H, Garrido-Ri'os AA, Sanz-Mun'oz C, MirandaRomero A (2009) Mondor's Disease. Clin Exp Dermatol 7: 753-756.

5. Alvarez-Garrido H, Garrido-Ríos AA, Sanz-Muñoz C, Miranda-Romero A (2009) Mondor's disease. Clin Exp Dermatol 34: 753-756.
6. Camiel MR, Benninghoff DL (1971) Mondor's disease in the breast. Superficial thrombophlebitis of the thoracoabdominal wall. J Natl Med Assoc 63: 352-353.

7. HONIG C, RADO R (1961) Mondor's disease--superficial phlebitis of the chest wall: a review of seven cases. Ann Surg 153: 589-591.

8. Green RA, Dowden RV (1988) Mondor's disease in plastic surgery patients. Ann Plast Surg 20: 231-235.

9. Boehlen F, Bader M, de Moerloose P (2004) Superficial thrombophlebitis of the chest wall associated with anticardiolipin antibodies: antiphospholipid syndrome or Mondor's disease? Lupus 13: 70-71.

10. Levi I, Baum M (1987) Mondor's disease as a presenting symptom of breast cancer. Br J Surg 74: 700.

11. Miller DR, Cesario TC, Slater LM (1985) Mondor's disease associated with metastatic axillary nodes. Cancer 56: 903-904.

12. Dirschka T, Winter K, Bierhoff E (2003) Mondor's disease: a rare cause of anterior chest pain. J Am Acad Dermatol 49: 905-906.

13. Roscher AA, Weinstein E (1980) The clinico-pathological spectrum of Mondor's disease: an important surgical entity. Int Surg 65: 325-329.

14. Salemis NS, Merkouris S, Kimpouri K (2011) Mondor's disease of the breast. A retrospective review. Breast Dis 33: 103-107.

15. Bejanga BI (1992) Mondor's disease: analysis of 30 cases. J R Coll Surg Edinb 37: 322-324.

16. Luis Rodríguez-Peralto J, Carrillo R, Rosales B, Rodríguez-Gil Y (2007) Superficial thrombophlebitis. Semin Cutan Med Surg 26: 71-76.

17. Luis Rodríguez-Peralto J, Carrillo R, Rosales B, Rodríguez-Gil Y (2007) Superficial thrombophlebitis. Semin Cutan Med Surg 26: 71-76.

18. Shetty MK, Watson AB (2001) Mondor's disease of the breast: sonographic and mammographic findings. AJR Am J Roentgenol 177: 893-896.

19. Leizerovicz A, Prandoni P, Decousus H (2011). Fondaparinux reduces all types of symptomatic thromboembolic complications in patients with superficial vein thrombosis in the legs: data from the CALISTO study. Blood 118: 2310.

20. Bauersachs RM (2013) Diagnosis and treatment of superficial vein thrombosis. Hamostaseologie 33: 232-240.

21. Di Nisio M, Wichers IM, Middeldorp S (2013) Treatment for superficial thrombophlebitis of the leg. Cochrane Database Syst Rev 4.

22. Decousus H, Prandoni P, Mismetti P, Bauersachs RM, Boda Z, et al. (2010) Fondaparinux for the treatment of superficial-vein thrombosis in the legs. N Engl J Med 363: 1222-1232.

23. Marchiori A, Verlato F, Sabbion P, Camporese G, Rosso F, et al. (2002) High versus low doses of unfractionated heparin for the treatment of superficial thrombophlebitis of the leg. A prospective, controlled, randomized study. Haematologica 87: 523-527. 